\title{
PENGENALAN KONSEP EKOWISATA DAN IDENTIFIKASI POTENSI WISATA ALAM BERBASIS EKOWISATA
}

\author{
Idah Kusuma Dewi ${ }^{1)}$, Suwarti ${ }^{2)}$, Sri Yuwanti²) \\ 1)Manajemen, STIEPARI, Semarang, Jawa Tengah, Indonesia \\ 2)Pariwisata, STIEPARI, Semarang, Jawa Tengah, Indonesia \\ Corresponding author : Idah Kusuma Dewi \\ E-mail : idahkusumadewi71@gmail.com
}

Diterima 27 Februari 2021, Direvisi 06 April 2021, Disetujui 07 April 2021

\begin{abstract}
ABSTRAK
Permasalahan pada masyarakat Kelurahan Patemon adalah kurangnya pengetahuan masyarakat tentang kepariwisataan khususnya pengetahuan ekowisata. Oleh sebab itu pengabdian kepada masyarakat ini memiliki tujuan membantu pemberdayaan masyarakat di Kelurahan Patemon, Kecamatan Gunungpati, Kota Semarang dan ikut berkontribusi dalam mengembangkan kesejahteraan masyarakatnya dengan kemajuan ilmu pengetahuan pada bidang kepariwisataan, memperkenalkan pengetahuan pariwisata berbasis eko wisata yang belum pernah diperoleh masyarakat Kelurahan Patemon dan membantu identifikasi potensi wisata alam yang masih tersembunyi dan bisa dipublikasikan agar bermanfaat untuk menambah pendapatan dan meningkatkan perekonomian masyarakat Patemon. Metode yang digunakan dalam kegiatan pengabdian berupa sosialisasi tentang konsep ekowisata dan praktek identifikasi potensi daya tarik wisata yang ada di Kelurahan Patemon. Masyarakat yang mengikuti sosialisasi diwakili oleh kelompok Karang Taruna dan Kelompok PKK. Kegiatan pengabdian ini bermitra dengan mahasiswa KKN dari Uness sejumlah 3 orang. Dari evaluasi oleh mahasiswa KKN Uness diperoleh kesimpulan bahwa masyarakat kelurahan Patemon membutuhkan pengetahuan tentang kepariwisataan khususnya ekowisata dan cara identifikasi potensi wisata. Hasil yang dicapai pada kegiatan pengabdian ini yaitu: (1) Bertambahnya pengetahuan peserta sosialisasi mengenai ekowisata. (2). Peserta sosialisasi dapat menentukan potensi daya tarik wisata di Kelurahan Patemon berbasis eko wisata. (3) Kelurahan Patemon memiliki daya tarik ekowisata.
\end{abstract}

Kata kunci: pemberdayaan masyarakat; ekowisata; potensi wisata

\begin{abstract}
This community service aims to help empower the community in Patemon Village, Gunungpati District, Semarang City and contribute to developing the welfare of its people by advancing science in the field of management and tourism. The second objective is to introduce tourism-based eco-tourism knowledge that has never been obtained by the people of Patemon Village and the third objective is to help identify the potential for natural tourism that is still hidden and can be published so that it is useful to increase income and improve the economy of the Patemon community. This community service activity is a request from the Patemon Village community to get education about tourism and explore tourist attractions and their development. Implementation of community service activities through socialization methods on the concept of eco-tourism and identification of potential tourist attractions in Patemon Village. The results of community service activities in the Patemon Village are (1) Increased knowledge of the community about tourism. (2). Recognizing the potential tourist attraction in the Patemon Village based on eco-tourism. (3) Kelurahan Patemon has a tourist attraction.
\end{abstract}

Keywords: community empowerment; ecotourism; tourism potential

\section{PENDAHULUAN}

Sejak pemerintah menggencarkan model pembangunan desa / kelurahan yang baru yaitu membangun desa/kelurahan berbasis wisata, budaya, dan ekonomi kreatif sekitar tahun 2017, maka setiap desa /kelurahan didukung untuk mulai mengidentifikasi potensi daya tarik wisata. Tujuan pemerintah adalah agar tiap desa/kelurahan setidaknya berusaha untuk memberdayakan masyarakatnya sendiri melalui kegiatan pariwisata, karena sektor pariwisata ternyata dapat meningkatkan perekonomian masyarakat desa/kelurahan (UU RI No.10 tahun, 2009). Hal tersebut merupakan langkah pemberdayaan masyarakat dengan perubahan sosial di mana masyarakat berubah ke arah yang lebih baik, memiliki daya atau kemampuan mencukupi kebutuhan hidup keseharian baik yang bersifat ekonomi maupun 
non ekonomi (Suharto Edi, 2014). Pilihan pemberdayaan masyarakat melalui kegiatan kepariwisataan memerlukan kebersamaan dalam mengelola operasional unit usaha wisatanya karena menyangkut kepentingan semua pihak (Citra Perdana, 2018).

Pemberdayaan masyarakat sendiri merupakan upaya mengangkat keberdayaan suatu masyarakat agar menemukan alternatif lain dalam melanjutkan pembangunan masyarakat dan memiliki pengertian yaitu memberdayakan masyarakat dari kondisi yang tidak mampu beralih ke kondisi memiliki daya atau mampu yang mengarah kepada perubahan kualitas hidup masyarakat yang lebih baik baik jasmani maupun rohani ( $A$. Faidlal Rahman, 2013). Mewujudkan pemberdayaan masyarakat tidak cukup hanya mengarah pada ekonomi tetapi harus mencakup nilai sosial dan adat budaya masyarakatnya agar terbangun pula ketahanan sosial budaya mengingat wisatawan yang berkunjung berasal dari wilayah lain dengan budaya yang berbeda (Anak Agung Istri Andriyani, Edhi Martono, Muhamad, 2017: 3).

Konsep ecotourism memiliki keunikan karena dapat menikmati keindahan alam terbuka sekaligus dapat merasakan budaya masyarakat setempat dalam kehidupan seharihari. Namun tetap harus dipahami oleh kalangan masyarakat bahwa ada aturan dan prinsip tertentu untuk kegiatan ekowisata (Ferdinal Asmin, 2011). Kegiatan ekowisata di Indonesia diatur dalam regulasi yaitu Peraturan Menteri Dalam Negeri Nomor 33, 2009, yang mengelompokkan wisata dalam lima kategori yaitu,wisata pemandangan, wisata petualangan, wisata kebudayaan dan sejarah, wisata penelitian serta wisata konservasi dan pendidikan (Mochammad Nafia, Bambang Supriadib, 2017).

Sedangkan yang dimaksud dengan potensi wisata secara umum adalah sesuatu hal yang sangat mungkin untuk dimunculkan sebagai pemikat wisatawan agar berkunjung ke daerah tersebut. Kebosanan pada bentuk wisata masa lalu yang berkonsep mass tourism merupakan peluang munculnya konsep ekowisata yang lebih membuka kesempatan untuk membaur dan berinteraksi serta berkomunikasi langsung dengan masyarakat setempat (Anak Agung Istri Andriyani, Edhi Martono, 2017).

Pemilihan konsep ekowisata dalam rangka pemberdayaan masyarakat Kelurahan Patemon dimaksudkan sebagai bentuk pariwisata yang lebih berkualitas dalam melestarikan lingkungan alam (Bambang Sunaryo, 2013). Atraksi ecotourism merupakan kegiatan pariwisata yang berbasis lingkungan dengan menggambarkan kegiatan wisata di alam bebas atau terbuka. Konsep untuk tetap menjaga eksistensi lingkungan alam terbuka dari kerusakan dan kepunahan makhluk yang berada di dalam lingkungan tersebut. Special Interest Tourism (SIT) adalah model pariwisata minat khusus yang berbasis alam dan peduli pada upaya pelestarian alam yang disebut dengan ekowisata.

Pembangunan masyarakat yang sudah berjalan, harus berkelanjutan dan tidak diperbolehkan mengganggu kearifan lokal dan budaya keseharian masyarakatnya serta beriringan dengan penerapan ekowisata, oleh sebab itu pengembangan pariwisata harus direncanakan dan dirancang dengan baik. Konsep tersebut merupakan sebuah bentuk tanggungjawab manusia terhadap kelestarian lingkungan alam sekaligus sebagai sumber pemberi manfaat ekonomi dan menjaga eksistensi budaya setempat. Ekowisata membuat masyarakat lokal mampu mengeksplorasi potensi - potensi wisata yang tersembunyi dan mendatangkan keuntungan serta menyelaraskan dengan memberikan edukasi berupa pendidikan lingkungan hidup kepada masyarakat maupun wisatawan yang berkunjung.

Ekowisata sebagai indikator ekonomi sesuai Peraturan Menteri Dalam Negeri Nomor 33 Tahun 2009 yang menyatakan bahwa kegiatan wisata alam di daerah dapat meningkatkan perekonomian masyarakat setempat dan memberikan dampak baik sekaligus buruk di sisi yang lain. Dampak baiknya berupa peningkatan kesejahteraan masyarakat dengan adanya peluang - peluang usaha sektor pariwisata sedangkan dampak buruknya jika tidak mempedulikan lingkungan alam terbuka, secara tidak langsung akan merusak budaya masyarakat yang tidak terkendali. Apalagi ditambah peran masyarakat sendiri yang belum memahami pentingnya kelestarian lingkungan seperti membuang sampah serampangan dan potensi munculnya bisnis wisata yang mengambil alih fungsi lingkungan sumber daya alam tidak terkontrol.

Kelurahan Patemon termasuk bagian dari wilayah Kecamatan Gunungpati Kota Semarang yang masih memiliki lingkungan alami asri. Karena statusnya kelurahan maka tidak mendapat alokasi dana seperti pedesaan. Oleh sebab itu, kegiatan pengabdian kepada masyarakat yang dilakukan di wilayah Kelurahan Patemon selain memberikan motivasi dan dukungan kepada kelompok masyarakat yang diwakili kelompok Karang Taruna dan PKK juga bagian dari upaya mewujudkan kampung wisata Patemon ditahun 
2019 dalam rangka membangun dan memberdayakan masyarakat.

Kegiatan pengabdian kepada masyarakat Patemon ini penting agar ada edukasi mengenai pengetahuan tentang kepariwisataan dan memiliki kemampuan mengidentifikasi potensi wisata untuk mengetahui atraksi apa saja yang dimiliki dan bisa diekspos sebagai daya tarik wisata Patemon. Atraksi wisata merupakan ciri khas unik yang tidak ditemui di tempat lain, berupa keaslian alam yang indah dan asri atau atau atraksi buatan manusia yang menarik minat untuk dikunjungi orang dari luar wilayah tersebut (R. Jati Nurcahyo dan Yulianto, 2019).

Berdasarkan latar belakang diatas, rumusan permasalahannya adalah:

1. Bagaimana meningkatkan pengetahuan dan pemahaman masyarakat tentang penerapan konsep ekowisata di wilayah Kelurahan Patemon, Kecamatan Gunungpati, Kota Semarang?

2. Bagaimana identifikasi potensi wisata di wilayah Kelurahan Patemon, Kecamatan Gunungpati, Kota Semarang?

\section{METODE}

Kegiatan pengabdian masyarakat ini berlokasi di Balai Kelurahan Patemon Kecamatan Gunungpati Kota Semarang yang dilaksanakan pada hari sabtu tanggal 1 september 2018. Acara berbentuk sosialisasi disusun dan dipandu oleh mahasiswa KKN Uness sebagai mitra dari tim pengabdian masyarakat STIEPARI Semarang. Peserta sosialisasi merupakan perwakilan dari kelompok masyarakat yaitu Kelompok Karang Taruna dan Kelompok PKK. Acara dimulai pukul 09.00 dan berakhir pukul 12.00 wibb. Peserta duduk lesehan beralas karpet di balai Kelurahan Patemon sejumlah 30 orang. Pelaksanaan acara dipandu oleh mahasiswa KKN Uness, diawali dengan pembukaan, sambutan selamat datang oleh lbu Pj. Kelurahan Patemon kemudian sambutan singkat oleh ketua Tim Pengabdian Masyarakat dilanjut doa.

Wujud kegiatan berikutnya berupa sosialisasi pengenalan dan penjelasan tentang konsep eko-wisata. Metode yang digunakan adalah sosialisasi dengan melibatkan secara langsung kelompok masyarakat yaitu Karang Taruna dan PKK. Sosialisasi pertama adalah penyajian materi tentang konsep eko-wisata. Waktu yang disediakan untuk sosialisasi konsep eko-wisata sekitar satu jam. Penjelasan dimulai dari pengetahuan dasar kepariwisataan. (Rai Utama I Gusti Bagus, 2016), istilah kepariwisataan yang disampaikan mencakup semua aktivitas manusia yang ditujukan untuk berwisata, ada interaksi dan komunikasi yang terjalin antara wisatawan dengan pengusaha transportasi wisata, pemilik usaha kuliner, souvenir dan pondok wisata atau homestay. Dilanjutkan penjelasan tentang berbagai pengertian ekowisata menurut pakar pariwisata maupun pakar ilmu lain yang memiliki kaitan. Termasuk tujuan eko-wisata, perbedaan mass tourism dengan sustainable tourism, prinsipprinsip eko-wisata, jenis eko-wisata dan karakteristik eko-wisatawan.

Selanjutnya diskusi dan tanya jawab. Peserta menanyakan seputar istilah dalam pariwisata. Selesai sesi tanya jawab tentang materi sosialisasi ekowisata, sesi berikutnya merupakan penyajian materi tentang identifikasi potensi daya tarik dan praktek identifikasi potensi. Kegiatan tersebut disediakan waktu sekitar satu setengah jam. Praktek identifikasi dimulai dari lingkungan RT/RW masing-masing peserta sosialisasi. Alat bantuan yang digunakan adalah kertas dan pensil. Peserta membentuk kelompok sesuai alamat rumah masing-masing. Perwakilan kelompok dari $\mathrm{Rt} / \mathrm{Rw}$ tersebut menuliskan atraksi yang ada di sekitar lingkungan $\mathrm{Rt} / \mathrm{Rw}$ tempat tinggalnya. Dalam kegiatan identifikasi tersebut, peta wilayah Kelurahan Patemon merupakan panduan utama untuk melihat lokasi Rt/Rw di mana atraksi berada dan hubungannya dengan lokasi yang lain.

Jalur - jalur yang menghubungkan antar atraksi tersebut nantinya saat dibutuhkan pengembangan wisata merupakan cikal bakal paket wisata Kelurahan Patemon. Kegiatan penggalian titik-titik potensi wisata yang dilakukan oleh warga setempat ke depan diharapkan mampu melahirkan kajian yang utuh mengenai potensi wisata yang sebenarnya ada dan bisa dikembangkan sesuai dengan pemahaman, kebutuhan dan kemampuan masyarakat. Dengan demikian tercapai keberdayaan masyarakat untuk membangun dirinya sendiri (Suharto Edi, 2014). Acara terakhir adalah kesimpulan praktek identifikasi dan penyampaian hasil identifikasi potensi serta penentuan daya tarik wisata di Kelurahan Patemon yang dilanjutkan dengan penutupan kegiatan sosialisasi pukul.12.00. wibb.

Berikut adalah bagan tahapan proses kegiatan pengabdian masyarakat di Kelurahan Patemon. 


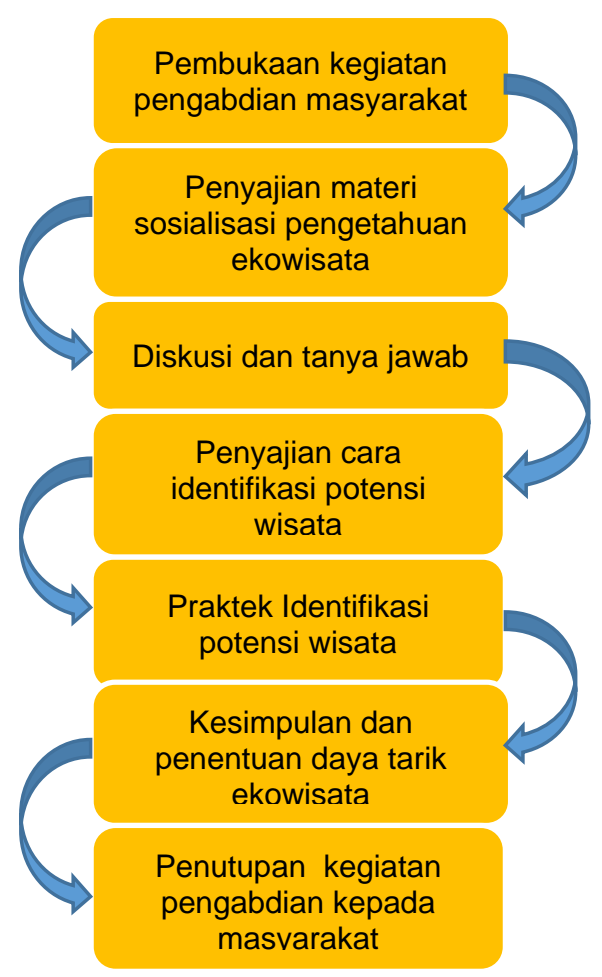

Gambar 1. Tahapan proses kegiatan pengabdian

\section{HASIL DAN PEMBAHASAN}

Pelaksanaan sosialisasi konsep ekowisata seperti yang tampak pada gambar 1 . Lokasi kegiatan sosialisasi berada di aula balai Kelurahan Patemon. Peserta duduk lesehan. Materi ditampilkan menggunakan model power point. Sesekali diselingi diskusi kecil karena ada pertanyaan yang langsung diajukan oleh peserta kegiatan yang sebagian besar remaja pemuda anggota Karang Taruna dan ibu-ibu anggota PKK. Penyampaian sosialisasi konsep ekowisata dan proses identifikasi potensi wisata membutuhkan waktu sekitar 3 jam.

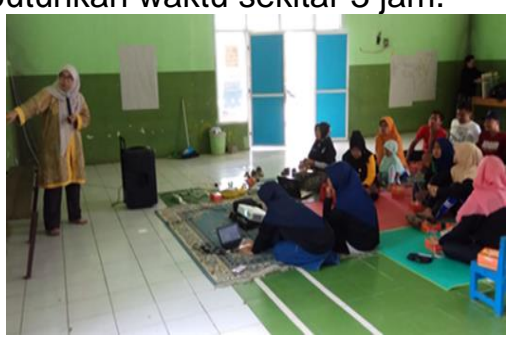

Gambar 2. Sosialisasi konsep eko wisata.Sumber: dok. pribadi

Secara umum makna istilah eko-wisata berasal dari ecology tourism, aktivitas wisata yang berfokus menikmati keindahan alam, baik buatan maupun asli. Namun wisatawan juga harus tahu tentang aturan dan persyaratan agar menjaga turut serta menjaga kebersihan lingkungan wisata, ikut serta melestarikan dan tidak merugikan ekosistim yang ada. Tujuan eko-wisata umumnya berupa edukasi bagaimana melindungi keberadaan alam agar tidak rusak karena dijadikan daerah tujuan wisata dalam rangka meningkatkan kesejahteraan masyarakat. Hal itu menyangkut jumlah kunjungan wisatawan yang berbeda antara daerah tujuan wisata model mass tourism dengan model ekowisata yang berkelanjutan. Mass tourism merupakan model kunjungan wisata beramai-ramai dalam jumlah besar, hampir tidak ada batasan jumlah pengunjung karena fokusnya market dan profit oriented tanpa peduli dengan kelestarian sumber daya alamnya (Nyoman SunartaNyoman Sukma Arida. 2017).

Sedangkan prinsip-prinsip ekowisata antara lain peduli dan memelihara keaslian lingkungan wisata, mencintai budaya dan kearifan lokal seperti budaya gotong royong namun tetap memberikan edukasi dan manfaat secara ekonomi (Lenny Yusrini, Nova Eviana, 2018). Karakteristik eko-wisatawan berupa kembali ke alam, memiliki kesinambungan tidak hanya sesaat, peduli lingkungan hayati, memberi manfaat edukasi dan ekonomi, mengesankan bagi wisatawan sehingga merasa puas berwisata ke lokasi tersebut (Muchlisin Riadi, 2019). Jenis-jenis ekowisata meliputi alam dan budaya, perorangan atau kelompok kecil, lokasi wisata yang sudah populer dan penggunaan waktu tinggal, seharian atau hanya beberapa menit.

Berdasarkan peta wilayah, Patemon memiliki kontur tanah yang berupa dataran tinggi dan sungai. Kondisi dataran tinggi masih alami ala suasana pedesaan, hijau,asri dan berhawa sejuk. Pemilihan konsep ekowisata sebagai wisata unggulan di Kelurahan Patemon sesuai dengan kondisi di wilayah tersebut. Karena konsep ekowisata sendiri adalah menjaga kelestarian alam sebagai tempat tinggal manusia dan makhluk hidup lainnya. Patemon memiliki delapan RW. Tiap RW memiliki sekitar 2 hingga 4 RT. Sebagian besar wilayah Kelurahan Patemon adalah peruntukan tanah sawah, pekarangan dan kebun. Air diperoleh dari sistim tampungan air hujan. Pekerjaan seadanya membuat taraf ekonomi warga atau masyarakat Patemon rendah dan secara otomatis berimplikasi terhadap tingkat kesejahteraan warga yang rendah dan nilai sosial budayanya (Anak Agung Istri Andayani, 2017).

Kegiatan berikutnya adalah memandu identifikasi potensi wisata yang ada dilingkungan $\mathrm{Rt} / \mathrm{Rw}$ peserta sosialisasi, seperti yang terlihat pada gambar 2 . Sebelum kegiatan identifikasi potensi dilakukan, disampaikan terlebih dulu apa tujuan dan fungsi identifikasi potensi atraksi yang ada dilingkungan wilayah Kelurahan Patemon. Identifikasi merupakan 
langkah awal warga mengenali situasi dan kondisi wilayah dan lingkungan sekitarnya sehingga memiliki gambaran nyata untuk proses pengembangan wisata nantinya (I.B.G. Pujaastawa, 2015).

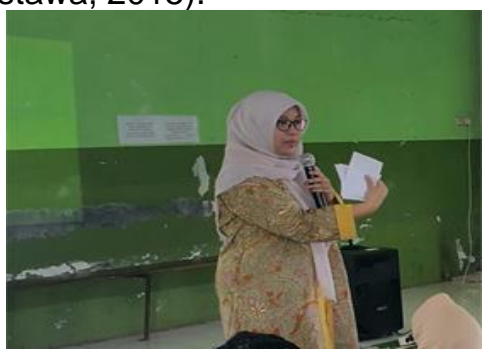

Gambar 3. Identifikasi potensi daya tarik. Sumber: dok. pribadi.

Hasil dari kegiatan identifikasi potensi dengan bantuan secarik kertas yang ditulisi nama wilayah RT/RW sesuai tempat tinggalnya serta menuliskan ada kegiatan masyarakat apa saja atau keunikan apa saja yang ada di lokasi tersebut. Temuan kesatu adalah potensi obyek wisata alam buatan yang disebut Embung Patemon, disebut juga danau buatan karena dibuat untuk menampung air hujan. Lokasinya berada di wilayah Rt. 01/Rw. 01.

Embung Patemon merupakan realisasi program 1000 embung Gubernur Jawa Tengah, Ganjar Pranowo. Embung itu sendiri milik Balai Besar Wilayah Sungai (BBWS) pada Kementerian Pekerjaan Umum (PU). Fungsi utama embung merupakan saluran irigasi tanaman holtikultura. Lokasi sekitar embung sudah sering juga dimanfaatkan oleh warga Patemon sebagai tempat atraksi hiburan serta rekreasi keluarga. Setiap hari minggu pagi di Embung Patemon rutin ada senam lansia dan ibu-ibu PKK serta kegiatan memancing di embung oleh beberapa warga.

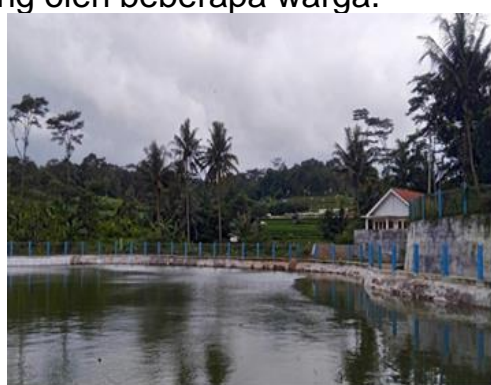

Gambar 4. Kondisi embung Patemon. Sumber: patemonsemarangkota.co.id

Metode identifikasi berupa deskriptif tentang jenis potensi wisata alamnya yang didiskusikan dengan model FGD (focus grup discussion) kemudian melakukan interview dan pendokumentasian. Peserta sosialisasi membentuk grup diskusi sesuai wilayah Rt/RW masing-masing untuk menganalisis apakah ada atraksi yang bisa menarik minat wisatawan ke Patemon, khususnya ke wilayah Rt/RWnya masing-masing. Embung adalah danau buatan manusia. Aspek yang diidentifikasi antara lain:

1. Lokasi embung.

2. Status kawasan embung.

3. Bagaimana akses menuju area embung.

4. Panorama di sekitar embung.

5. Kegiatan yang dilakukan di kawasan embung.

6. Fungsi embung untuk warga Patemon.

7. Bagaimana kebijakan pemerintah jika embung dibuat daya tarik wisata di Kelurahan Patemon.

8. Dampak baik dan buruk terhadap lingkungan jika embung dinyatakan sebagai daya tarik wisata berbasis ekowisata.

9. Fasilitas yang tersedia dilingkungan embung.

Wisata Embung Patemon sebagai potensi wisata masih membutuhkan fasilitas penunjang dan pendukung seperti sumber daya manusia sebagai guide dan upaya promosi wisata Embung Patemon. Atraksi wisata bisa lebih optimal dalam memberikan peningkatan kesejahteraan bagi masyarakat jika tanpa merusak lingkungan juga tanpa mengubah kemurnian bangunan maupun tatanan sosial dan budaya masyarakat setempat (Faris Zakaria dan Rima Dewi Suprihardjo, 2014).

Daya tarik Embung Patemon adalah kondisi sekitarnya yang masih memiliki pemandangan khas pedesaan, meskipun masuk wilayah Kota Semarang, dan akses menuju Embung yang dekat dengan jalan raya sehingga mudah dijangkau oleh pengunjung di luar Patemon. Faktor itu menjadikan kawasan embung harus dikelola dengan manajemen yang baik, transparan dan sesuai peraturan agar tidak melenceng dari konsep ekowisata. Kelompok Sadar Wisata perlu segera dibentuk dan melakukan sosialisasi sapta pesona dan sadar wisata kepada masyarakat (Firmansyah Rahim-Kemenpar, 2012). Kesadaran masyarakat mengenai peran dan tanggung jawabnya terhadap pengelolaan wisata diawali dari kiprah Kelompok Sadar Wisata yang disingkat POKDARWIS sebagai ujung tombak pariwisata (Winda Amilia,Rokhani,Rendra C. Prasetya, 2020).

Temuan kedua adalah makam Kyai Cagak Luas atau Syaikh Sulaiman yang berada di Jalan Kauman no 1 (belakang Pesantren Al Asror) Kelurahan Patemon, yang merupakan sesepuh dari cikal bakal Kelurahan Patemon. Makam tersebut jelas memiliki potensi wisata rohani yang tidak bisa disepelekan sehingga harus dikelola dengan baik agar bermanfaat dari sisi pariwisata, sisi ekonomi selain sisi religiusnya (Ahsana Mustika Ati, 2011). Wisata rohani berkaitan dengan budaya setempat 
tentang kepercayaan atau keyakinan yang dianut masyarakatnya secara turun temurun dan masih dirawat serta dipelihara hingga kini karena keistimewaannya pada jaman dahulu (Yeni Muharromatun Suroya, 2020).

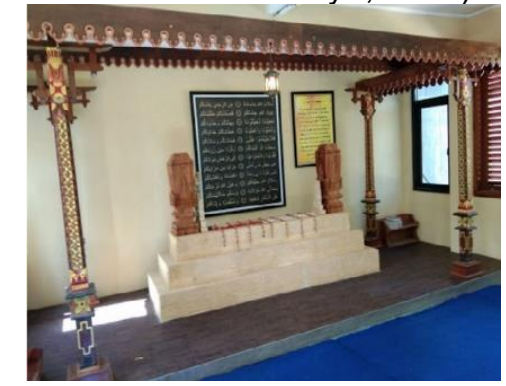

Gambar 5 . Maqam Kyai Cagak Luas Patemon. Sumber: Laduni.id. berikut:

Aspek yang diidentifikasi adalah sebagai

1. Nama makam dan storytellingnya.

2. Status makam.

3. Fasilitas yang tersedia di lokasi maqam.

4. Persepsi masyarakat setempat tentang maqam tersebut.

5. Event kunjungan ke makam.

6. Sikap pemerintah setempat tentang makam sebagai wisata ziarah.

7. Akses menuju makam.

8. Dampak baik dan buruk terhadap lingkungan jika makam Kyai Cagak luas dinyatakan sebagai daya tarik wisata.

Makam Kyai Cagak Luas merupakan potensi wisata religi yang bisa dikelola lebih baik dengan merancang kolaborasi aktivitas wisata yang lain selain pengajian atau haul. Istilahnya adalah pengembangan wisata berkelanjutan yang tetap memperhatikan prinsip-prinsip ekowisata agar kepuasan wisatawan terjaga dan memiliki pengalaman mengesankan supaya kembali lagi melakukan rekreasi sebagai tujuan destinasi wisatanya.

Temuan ketiga adalah program penanaman tanaman berkhasiat yaitu beragam TOGA (tanaman obat keluarga) dilingkungan Balai Kelurahan Patemon yang diwacanakan sebagai potensi daya tarik wisata yang lain dan memberikan manfaat ganda untuk kesehatan. Tanaman yang biasanya tumbuh liar bisa berfungsi sebagai obat herbal yang bermanfaat untuk menjaga kesehatan bahkan untuk penyembuhan terhadap suatu penyakit (Susi Mindarti-Bebet Nurbaeti, 2015). Rancangannya adalah di setiap rumah penduduk memiliki TOGA sebagai daya tarik wisata pengunjung ke lokasi Kelurahan Patemon. Toga yang ditanam dipilih yang memiliki khasiat untuk kesehatan, kecantikan dan kesehatan.

Aspek yang diidentifikasi yaitu:

1. Nama lokasi.
2. Status lokasi.

3. Event kegiatan.

4. Akses menuju lokasi Toga.

5. Persepsi masyarakat terhadap potensi wisata tersebut.

6. Fasilitas yang tersedia di lokasi TOGA.

7. Kebijakan pemerintah setempat sebagai dukungan.

8. Dampak baik dan buruk jika kebun TOGA dijadikan sebagai daya tarik wisata Patemon.

Kebun TOGA yang sengaja ditanami aneka tumbuhan berkhasiat sebagai herbal merupakan potensi daya tarik wisata. Terlebih lagi suasana sejuk dan lingkungan asri wilayah Kelurahan Patemon serta tanah yang subur , sangat mendukung tumbuh kembangnya tanaman TOGA.

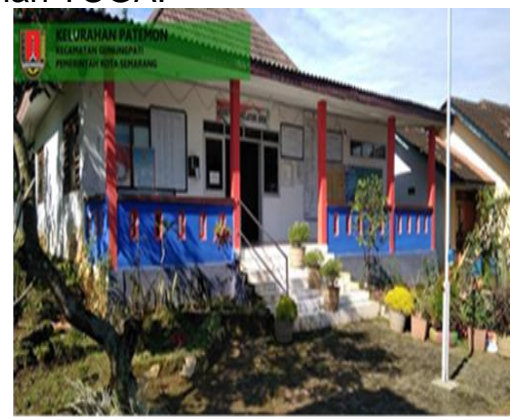

Gambar 6. Kebun Toga disamping Kantor Kelurahan Patemon. Sumber: dok.pribadi.

\section{SIMPULAN DAN SARAN}

Simpulan dari kegiatan diatas, kelompok masyarakat yaitu Karang Taruna dan PKK sudah memahami apa yang dimaksud dengan potensi wisata berbasis eko-wisata dan berhasil menentukan tiga daya tarik wisata alam buatan dengan konsep eko-wisata yaitu Embung Patemon yang berada di RT01/RW01 Kampung Sriging, Makam Kyai Cagak Luas dan Kebun Toga. Saran dari hasil FGD yang pertama sebagai berikut, diperlukan pemberian kesempatan untuk mengikuti pelatihan kewirausahaan agar dapat memanfaatkan peluang usaha pariwisata yang muncul dan mewujudkan peningkatan kesejahteraan bagi masyarakat. Usaha-usaha kecil yang muncul karena memenuhi kebutuhan wisatawan di lokasi wisata dikoordinasi secara menyeluruh dengan partisipasi penuh dari masyarakat dan dukungan stakeholder serta pemerintah setempat (K. Sukirman, 2017). Sebagai saran kedua adalah problem penanganan sampah di lokasi wisata harus mendapatkan perhatian yang serius dan terpadu agar tidak mencemari lingkungan sekitarnya (Karlita Ayu Suntari, Budi Heri Pirngadi, 2018). Saran ketiga adalah pemenuhan keberadaan homestay diperlukan untuk kebutuhan live in wisatawan yang ingin 
berinteraksi lebih jauh dengan alam dan penduduknya (Kemenpar, 2018).

\section{UCAPAN TERIMAKASIH}

Terimakasih kepada pihak P3M yang telah membiayai kegiatan Pengabdian kepada Masyarakat di Kelurahan Patemon dan terimakasih pula kepada pihak Kelurahan Patemon beserta jajarannya yang mendukung kegiatan sosialisasi konsep ekowisata serta terimakasih atas perhatian dan partisipasi warga yang diwakili kelompok Karang Taruna dan PKK dalam upaya memberdayakan masyarakat dan meningkatkan kesejahteraan ekonomi melalui pariwisata dengan tema konsep ekowisata.

\section{DAFTAR RUJUKAN}

A. Faidlal Rahman (2013) 'Pemberdayaan Masyarakat Melalui Pengembangan Desa Wisata', Jurnal Media Wisata ISSN 16935969 / EISSN 26858436. Available at: https://amptajurnal.ac.id/index.php/MW S/article/view/48/47.

Ahsana Mustika Ati (2011) 'Pengelolaan Wisata Religi (Studi Kasus Makam Sultan Hadiwijaya Untuk Pengembangan Dakwah)'. Available at: http://library.walisongo.ac.id/digilib/files /disk1/124/jtptiain-gdl-ahsanamust6189-1-fileskr-i.pdf.

Anak Agung Istri Andriyani, Edhi Martono, M. (no date) 'Pemberdayaan Masyarakat Melalui Pengembangan Desa Wisata Dan Implikasinya Terhadap Ketahanan Sosial Budaya Wilayah(Studi Di Desa Wisata Penglipuran Bali)'. Available at: https://www.researchgate.net/publicati on/317384474_Pemberdayaan_Masya rakat_Melalui_Pengembangan_Desa_ Wisata_Dan_Implikasinya_Terhadap_ Ketahanan_Sosial_Budaya_Wilayah_ Studi_Di_Desa_Wisata_Penglipuran_Bali.

Bambang Sunaryo (2013) Kebijakan pembangunan destinasi pariwisata: konsep dan aplikasinya di Indonesia, ISBN: 6027869208, 9786027869202.

Citra Perdana (2018) 'PERENCANAAN PARIWISATA DALAM PEMBANGUNAN WILAYAH BERKELANJUTAN TEORI DAN PRAKTIK'. Available at: http://repository.lppm.unila.ac.id/13278 /1/BUKU-PERENC-PARIWISATACITRA.pdf.

Faris Zakaria dan Rima Dewi Suprihardjo (2014) 'Konsep Pengembangan Kawasan Desa Wisata di Desa
Volume 4, Nomor 2., April 2021. p-ISSN : 2614-5251

e-ISSN : 2614-526X

Bandungan Kecamatan Pakong Kabupaten Pamekasan', JURNAL TEKNIK POMITS, Vol. 3, No. Available at:

https://media.neliti.com/media/publicati ons/194629-ID-konsep-

pengembangan-kawasan-desawisata.pdf.

Ferdinal Asmin (2011) 'Ekowisata dan Pembangunan Berkelanjutan: Dimulai dari Konsep Sederhana'. Available at: https://www.researchgate.net/publicati on/323309174_Ekowisata_dan_Pemb angunan_Berkelanjutan_Dimulai_dari_ Konsep_Sederhana .

Firmansyah Rahim-Kemenpar (2012) 'Pedoman Kelompok sadar wisata'. Available at: https://www.kemenparekraf.go.id/asset _admin/assets/uploads/media/old_all/1 Pedoman Pokdarwis.pdf.

I.B.G. Pujaastawa, I. N. A. (2015) Pedoman Identifikasi Potensi Daya Tarik Wisata. Available at: https://simdos.unud.ac.id/uploads/file penelitian_1_dir/841b7cc9cce0e06044 0607f8ad822f72.pdf .

K. Sukirman (2017) 'JIWA KEWIRAUSAHAAN DAN NILAI KEWIRAUSAHAAN MENINGKATKAN KEMANDIRIAN USAHA MELALUI PERILAKU KEWIRAUSAHAAN', Universitas Muria Kudus, 20, n. Available at: https://www.researchgate.net/publicati on/316626169_Jiwa_Kewirausahaan_ dan_Nilai_Kewirausahaan_Meningkatk an_Kemandirian_Usaha_melalui_Peril aku Kewirausahaan.

Karlita Ayu Suntari, Budi Heri Pirngadi, D. S. (2018) 'TINGKAT PENGELOLAAN SAMPAH OLEH MASYARAKAT DI KAWASAN PERKOTAAN CIWIDEY', Perencanaan Wilayah dan Kota, Fakultas Teknik, Universitas Pasundan Jl. Setiabudhi 193, Bandung, Indonesia. March 2018.2 DOI: 10.23969/planologi.v5i1.929. Available at: https://www.researchgate.net/publicati on/325491703_Tingkat_Pengelolaan Sampah_oleh_Masyarakat_dl_Kawas an_Perkotaan_Ciwidey.

Kemenpar (2018) 'Panduan Pengembangan Homestay Desa Wisata Untuk Masyarakat'. Available at: https://www.kemenparekraf.go.id/asset _admin/assets/uploads/media/pdf/medi a_1592238115_Panduan_Pengemban gan_Homestay_Desa_Wisata_Untuk_ Masyarakat.pdf. 
Mochammad Nafia, Bambang Supriadib, N. R.

(2017) Pengembangan Ekowisata Daerah. Available at: https://www.researchgate.net/profile/B ambang_Supriadi/publication/3207263 10_Pengembangan_Ekowisata_Daera

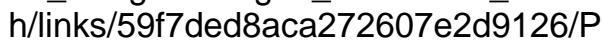
engembangan-Ekowisata-Daerah.pdf.

R. Jati Nurcahyo dan Yulianto (2019) 'Pengembangan Daya Tarik Wisata Kunjung Museum Melalui Wahana Edukasi Di Museum Pura Pakualaman Yogyakarta', Journal Of Tourism And Economic, Vol. 2, No. Available at: https://repository.bsi.ac.id/index.php/un duh/item/290472/JOURNAL-OF-

TOURISM-AND-ECONOMIC--MEI2019.pdf.

Rai Utama I Gusti Bagus (2016) 'Pariwisata dan Keilmuannya'. doi: DOI: 10.13140/RG.2.2.16319.30887 :

Suharto Edi (2014) 'Membangun Masyarakat Memberdayakan Rakyat: Kajian Strategis Pembangunan Kesejahteraan Sosial dan Pekerjaan Sosial'. Available at: https://difarepositories.uinsuka.ac.id/246/1/Membangun Masyarakat Memberdayakan Rakyat.pdf.

Susi Mindarti-Bebet Nurbaeti (2015) BUKU SAKU Tanaman Obat Keluarga (TOGA). Available at: http://perpustakaan.pertanian.go.id/rep ository_litbang/uploaded_files/BPTP_J abar/lsi_BukuSaku_Toga.pdf : .

UU RI No.10 tahun (2009) 'Kepariwisataan’.

Winda Amilia,Rokhani,Rendra C. Prasetya, B. S. (2020) 'PEMBANGUNAN DESA WISATA GADINGAN DAN KEBUTUHAN PENGEMBANGAN SUMBER DAYA MANUSIA DALAM PENDEKATAN COMMUNITY BASED TOURISM', JURNAL PENGABDIAN $D A N$ PEMBERDAYAANMASYARAKATISS $N$ : 2549-8347 (Online), ISSN: 25799126 (Print), Volume 4,N. Available at: file://C:/Users/ASUS/Downloads/Pem bangunan_Desa_Wisata_Gadingan_d an_Kebutuhan_Pen.pdf.

YENI MÜHARROMATUN SUROYA (2020) 'MANAJEMEN WISATA RELIGI DALAM MENINGKATKAN DAYA TARIK MAKAM RAJA PANJALU CIAMIS JAWA BARAT'. Available at: http://repository.iainpurwokerto.ac.id/6 913/1/COVER_ABSTRAK_DAFTAR ISI_BAB I_BAB V_DAFTAR PUSTAKA.pdf. 